\title{
Socioeconomic, comorbidity, lifestyle and quality of life comparisons between chronic rhinosinusitis phenotypes: Data from the National Chronic Rhinosinusitis Epidemiology Study
}

\author{
Carl Philpott ${ }^{1,2}$, Tanya Ta ${ }^{2,3}$, Clair Hopkins ${ }^{4}$, Jaydip Ray ${ }^{5}$, Shahzada Ahmed ${ }^{6}$, Robert \\ Almeyda $^{7}$, Naveed Kara ${ }^{8}$, Sean Carrie $^{9}$, S. E. Erskine ${ }^{2}$, Russell Cathcart ${ }^{10}$, Vishnu \\ Sunkaraneni $^{11}$, Alasdair Robertson ${ }^{12}$, Shahram Anari ${ }^{13}$, B Kumar ${ }^{14}$, and Allan Clark ${ }^{2,3}$ \\ ${ }^{1}$ University of East Anglia \\ ${ }^{2}$ University of East Anglia Faculty of Health \\ ${ }^{3}$ UEA Rhinology \& ENT Group \\ ${ }^{4}$ Guy's and Saint Thomas' Hospitals NHS Trust \\ ${ }^{5}$ Sheffield Teaching Hospitals NHS Foundation Trust \\ ${ }^{6}$ University Hospitals Birmingham NHS Foundation Trust \\ ${ }^{7}$ Royal Berkshire NHS Foundation Trust \\ ${ }^{8}$ County Durham and Darlington NHS Foundation Trust \\ ${ }^{9}$ Newcastle Upon Tyne Hospitals NHS Foundation Trust \\ ${ }^{10}$ Jersey General Hospital \\ ${ }^{11}$ Royal Surrey County Hospital NHS Foundation Trust \\ ${ }^{12}$ Southern General Hospital \\ ${ }^{13}$ Heart of England NHS Foundation Trust \\ ${ }^{14}$ Wrightington Wigan and Leigh NHS Foundation Trust
}

October 1, 2020

\begin{abstract}
Background: Chronic rhinosinusitis (CRS) is a heterogenous group of inflammatory sinonasal disorders with key defining symptoms, but traditionally separated into phenotypes by clinical/endoscopic findings. It is not known if the two phenotypes have differing socioeconomic, co-morbidity and lifestyle differences. Objective: This analysis of the Chronic Rhinosinusitis Epidemiology Study (CRES) database sought to analyse any key differences in the socioeconomic variables between those with CRS with nasal polyps (CRSwNPs) and those without nasal polyps (CRSsNP). We also sought to analyse differences in comorbidities, lifestyle and quality of life. Methods: Patients with a confirmed diagnosis of CRS in secondary and tertiary care outpatient settings were invited to participate in a questionnaire based case-control study. Variables included demographics, comorbidities, socioeconomic factors, lifestyle factors and health related quality of life. Results: A total of 1204 patients' data were analysed; $553 \mathrm{CRSsNP}$ and $651 \mathrm{CRSwNP}$ participants. The key socioeconomic variables did not demonstrate any notable differences, nor did lifestyle variables other than alcohol consumption being higher in those with CRSwNP ( $\mathrm{p}=0.032)$. Aside from confirmation of asthma being more common in CRSwNP, it was notable that this group complained less of URTIs and CRSsNP participants showed evidence of lower HRQoL scores in respect of body pain ( $\mathrm{p}=0.001)$. Conclusions: Patients with CRSwNP experience higher rates of asthma and lower rates of URTIs but otherwise do not demonstrate significant socioeconomic, comorbidity, lifestyle or quality of life issues other than for body pain and alcohol consumption.
\end{abstract}




\section{Introduction}

\section{BACKGROUND:}

Chronic rhinosinusitis (CRS) is a common condition of the upper respiratory tract(1) with poor quality of life and known associations with the lower respiratory tract(2). It is known that socioeconomic deprivation can be associated with a higher prevalence of asthma and poorer lung function $(3,4)$. The Chronic Rhinosinusitis Epidemiology Study (CRES) was designed to distinguish differences in socio-economic status, geography, medical/psychiatric co-morbidity, lifestyle and overall quality of life between patients with CRS and healthy controls. Our previous analysis of the CRES dataset did not show evidence of any socioeconomic disparity between CRS cases and controls(5) and this was corroborated by a recent systematic review that found smoking was the only key association (6). However, given the differing rates of asthma in the two main phenotypes of CRS (2), it is possible that disparities between these two phenotypes exist. Smoking does not appear to differ between phenotypes both in our recent analysis and a larger dataset ${ }^{7,8}$. Other studies have considered socioeconomic variables but have not usually compared the two main phenotypes $(9,10)$. The latter review by Geramas et al ${ }^{10}$ showed an association in some studies between CRS and low socioeconomic status but not all studies relied on clinicians confirming the diagnosis of CRS, as is the case in the CRES ${ }^{11}$.

Previous analyses of the CRES dataset have considered quality of life, mood disturbances, rates of surgery and revision surgery, use of medication, rates of allergy, asthma, aspirin sensitivity and Eustachian tube dysfunction and the role of dietary salicylates and smoking, as well as qualitative analyses $(2,7,12-21)$. The aim of the analysis of the CRES database presented here was to specifically compare these variables between the two phenotypes of CRS, as this was not a feature of our original analysis(5), and for any variables not examined in any of the subsequent analyses that appeared worthy of closer examination.

\section{Methods}

This study has been reported in accordance with the STROBE statement guidelines for the reporting of observational studies. The study was sponsored by the University of East Anglia (UEA) and funded by the Anthony Long and Bernice Bibby Trusts. Ethical approval was granted by the Oxford C Research Ethics Committee (Ref: 07/H0606/100).

\section{Study Design}

The CRES was a prospective, questionnaire-based, case-control study conducted between October 2007 and September 2013 at thirty tertiary/secondary care sites across the United Kingdom. Patients with diagnosed CRS alongside healthy control subjects were asked to complete a single, study-specific questionnaire, capturing a variety of demographic and socio-economic variables, environmental exposures and medical comorbidities (See appendix 1).

\section{Participants and Data Sources}

Prospective participants were identified for recruitment at ENT outpatient clinics at 30 participating centres. Patients with CRS were examined by an ENT clinician and classified into CRS phenotypes (CRSwNPs, CRSsNPs or allergic fungal rhinosinusitis (AFRS) as per EPOS 2012 criteria(22) (see CRS participant section below). Healthy controls were recruited from family members of patients attending ENT clinics as well as members of hospital staff at recruitment sites.

Questionnaires were completed during the clinic visit or taken home to be completed and returned by prepaid post. No participant identifiable data was captured therefore consent was not required although it was implied through return of the questionnaire. Returned questionnaires were scanned and the data imported into in 
an electronic database in Microsoft Excel. Records in the database were compared to physical copies of the questionnaires by two members of the research team to ensure accuracy and consistency between the two.

All CRS participants and healthy controls were required to meet the inclusion/ exclusion criteria outlined below:

\section{CRS Participants}

\section{Inclusion Criteria}

Criteria for diagnosis of CRS with or without polyps (EPOS 2012 guidelines - as were relevant at the time of study $)(22)$

At least two symptoms must be present for at least 12 weeks and include:

- One of either nasal blockage/obstruction/congestion and/or nasal discharge (anterior/posterior nasal drip)

- and either facial pain/pressure and/or reduction or loss of sense of smell

and additionally:

- endoscopic signs of: polyps and/or mucopurulent discharge primarily from middle meatus; and/or oedema/mucosal obstruction primarily in middle meatus

- and/or CT changes: mucosal changes within the ostiomeatal complex and/or sinuses

Patients were then classified as having chronic rhinosinusitis without polyps (CRSsNPs), chronic rhinosinusitis with nasal polyps (CRSwNPs) or allergic fungal rhinosinusitis (AFRS); patients with the latter were not included in this analysis.

\section{Healthy Control Participants}

\section{Exclusion Criteria}

- Prior history of recurrent acute or chronic rhinosinusitis.

- Any other nose/sinus disorders e.g. allergic rhinitis (hayfever).

- Active medical problems that have required a hospital visit within the last 12 months.

\section{Exclusion Criteria for Both Groups}

- Patients/controls unable to comprehend written English.

- Patients/controls under the age of 18 years.

\section{Quantitative Variables and Bias}

The detailed questionnaire can be seen in appendix 1. The variables considered here in this updated analysis include:

1. The presence of comorbidities including asthma, chronic obstructive pulmonary disease (COPD), bronchiectasis, diabetes, hypothyroidism, autoimmune diseases, immunodeficiency and ciliary dysmotility

2. Quality of life as recorded by the domains of the SF-36.

3. Socioeconomic variables including mean index of multiple deprivation (IMD), mean household income, household occupancy and education level.

4. Lifestyle factors including smoking, alcohol and urban or non-urban domestic location 


\section{Sample Size Calculation}

The sample size calculation was based on the original primary outcome of the study which was to look for common associations between socioeconomic factors and $\mathrm{CRS}^{11}$. For socio-economic scores, the standard approach is to compare the proportion of subjects in the lower social classes to everyone else. In order for the study to have $80 \%$ power to detect a difference of $10 \%$ in "low social class" between controls and CRS participants, assuming a $30 \%$ rate in the CRS participants, with approximately 5 CRS participants to 1 control patient, 965 CRS participants and 193 controls were required ${ }^{(19)}$.

\section{Statistical Methods}

Patient demographics were summarised by CRS phenotype status using mean and standard deviation for continuous variables and the number and percentage for categorical variables. For the comparisons between the two phenotypes we planned the following analyses:

1. Comorbidities - comparisons using logistic regression and adjusting for age and sex of the rate of:

2. asthma

3. $\mathrm{COPD}$

4. bronchiectasis

5. URTIs per year

6. diabetes

7. hypothyroidism

8. immunodeficiency

9. autoimmune diseases

10. ciliary dysmotility

11. Quality of life: Comparing the mean SF-36 Score, its subscales (vitality, physical function, bodily pain, general health perceptions, physical role functioning, emotional role functioning, social role functioning and mental health) and its summary score (physical health and mental health) between the two groups using regression, adjusting for age and sex.

12. Socio-economic status:

13. Mean index of multiple deprivation (IMD) using regression, adjusting for age and sex

14. Mean household income using regression, adjusting for age and sex

15. Median household occupancy using a Mann-Whitney test

16. Education level using a Chi-squared test for individual levels and an odds ratio for grouped levels of GSCE/A-Level and Degree/Higher Degree.

17. Lifestyle and environmental exposure were compared using a Chi-Squared test

18. Comparison of alcohol consumption

19. Comparison of smoking rates

20. Comparison of the percentage of people who live in a village

All analyses were conducted using Stata MP 16.0.

\section{Results}

\section{Study Participants}

A total of 1535 questionnaires were returned with 1470 considered eligible for inclusion after removal of duplicates and questionnaires with missing data; only CRSwNP and CRSsNP cases were included in this analysis (see figure 1). This analysis is therefore based on the 1204 CRS participants who completed the relevant parts of the questionnaire. The overall response rate of those identified to take part in the study was $66 \%$ of those distributed. 


\section{Descriptive Data}

For the purpose of this analysis, participants with AFRS were not analysed due to smaller numbers of cases in the database. As such, there were 553 participants with CRSsNPs and 651 participants with CRSwNPs. The mean age of CRSsNP participants was 52 years (range 18-84) and of CRSwNP participants was 56 years (range 18-102). CRSsNP and CRSwNP participants were $53 \%$ and $31 \%$ female respectively; 65 and 77 participants in those two phenotypes respectively did not declare their sex.

\section{Primary Outcome Data and Main Results}

\section{Co-morbidities (table 1)}

There were significant differences in asthma, with those with CRSwNP having more than three times the odds of having asthma compared to those with $\operatorname{CRSsNP}(2)$. Other statistically significant differences included autoimmune disorders being more common in CRSsNP and with CRSwNP patients more likely to say they "never" or "seldom" suffered an URTI.

\section{Quality of life (table 2)}

Most of the domains showed a statistically significant difference in the unadjusted analysis however, only a difference in body pain $(\mathrm{p}=0.001)$ between those with polyps and those without remained between the groups after adjusting for age and sex. Therefore, worse scores were observed in those with CRSsNP for body pain only.

\section{Socioeconomic status (table 3 )}

There was no evidence of a difference in deprivation $(\mathrm{p}=0.787)$, income $(\mathrm{p}=0.424)$, household occupancy $(\mathrm{p}=0.43)$ or educational qualification $(\mathrm{p}=0.251)$ between those with polyps and those without. Figure 2 demonstrates the distribution of household income across both groups.

\section{Lifestyle variables (table 4)}

The comparison of the two phenotypes showed no evidence of a difference in smoking $(\mathrm{p}=0.25)$ or home location $(\mathrm{p}=0.12)$, but did show a difference in alcohol consumption, with CRSwNP participants likely to drink more alcohol than those with CRSsNP $(\mathrm{p}=0.032)$.

Discussion

Key results:

No demonstrable differences were found for the key socioeconomic variables between the two groups, nor were there any differences in lifestyle variables other than alcohol consumption being higher in those with CRSwNP. Aside from confirmation of asthma being more common in CRSwNP, it was notable that this group complained less of URTIs. CRSsNP participants showed evidence of lower HRQoL scores in respect of body pain. The difference in alcohol consumption may be explained by the gender differences. In the UK men consume more alcohol than women. The 2018 Health Survey for England showed the mean male weekly alcohol consumption in units was 15.5 while for females it was $9^{23}$. The same survey also found that $14 \%$ of male responders were teetotal compared to $21 \%$ of female responders. Our data shows that males are significantly more likely to suffer from CRwNP than females. 


\section{Interpretation:}

CRES is the largest epidemiological study of CRS and the first study since the 2001 Sinonasal Audit (24) to collect detailed information on socioeconomic variables in the UK. As mentioned above, a systematic review in 2018 concluded that smoking, social deprivation and low socioeconomic level appear to have a direct correlation with rhinosinusitis ${ }^{10}$. They also concluded that education level, and exercise and diet appear to have a more complex relationship with CRS. In the Korean KNHANES study CRSwNP was more prevalent in rural areas and with a lower level of education, obesity, increased amounts of smoking and alcohol consumption, and comorbid asthma ${ }^{8}$. It is possible that some of these difference are accounted for by ethnic differences in the underlying pathophysiology ${ }^{25}$.

A small study ( $\mathrm{n}=186$ ) comparing patients with AFRS and CRS found that he CRS cases were predominantly white and older at the time of diagnosis with higher income levels. They found no associations between disease severity, socioeconomic status, and demographic factors within the CRS groups ${ }^{26}$. In a North American study published in 2019, Beswick et al reported that their analysis of 392 patients showed that medical insurance status and male gender were significantly associated with worse smell test scores, and also that higher household income and lower age led to better outcomes on health related quality of life scores (SNOT22 ) following sinus surgery (27). In this study $36 \%$ of the cases were CRS with nasal polyps (CRSwNP) and $37 \%$ reported asthma. Differing findings and differing diagnostic and sampling methods across various studies and healthcare systems suggest that the true picture has yet to be clarified.

Whilst our CRES study has not demonstrated any evidence that socioeconomic deprivation is a risk factor for CRS or either of the two main phenotypes, other related work on the cost of managing CRS has shown higher out-of-pocket expenditure, primary care and secondary care utilisation, and time lost from work compared to those without $\mathrm{CRS}^{28}$. This study estimated an annual average out of pocket expenses of £304.84 secondary to CRS over 3 months, with a 5.3-fold greater spending on over-the-counter medication when compared to the general population and an association with an average 18.7 missed workdays per year. For those in lower socioeconomic groups, they are more likely to be disadvantaged by this implication. This effect appears to have been more pronounced in a private healthcare system (27) but may be less apparent in the National Health Service where direct healthcare is free at the point of service, excluding prescription costs (England not Scotland).

It is an interesting observation that those with CRSwNP reported higher rates of alcohol consumption than those with CRSsNP given our previous analysis regarding symptom exacerbation with wine, which showed significantly higher rates in the CRSwNP phenotype (29). This association between dietary salicylates and symptom exacerbation requires further investigation to better understand the link and the presence of any dose-dependent response.

\section{Limitations}

The CRES study design has certain limitations, whilst the diagnosis was made by a clinician, the remaining data was self-reported and may therefore predispose to recall bias. Secondly although we collected information on household occupancy, we didn't collect information on number of bedrooms and the potential for overcrowding. In asthma, overcrowding has been shown to have a positive ${ }^{30}$ and a negative ${ }^{31}$ correlation with respiratory symptoms with no clear relationship in other studies ${ }^{32}$, so there is not a clear relationship in the lower respiratory tract. Our study has also sampled a mainly British White ethnic demographic and may not fully reflect the wider population in the UK today.

\section{Generalisability}

CRES is a cross sectional UK based study incorporating a variety of the CRS population from across the country presenting to secondary care. The CRES study does not necessarily capture the whole CRS spectrum as mild sufferers may be managed by primary care alone and may therefore be underrepresented. In 
contrast to other studies, CRS was diagnosed by ENT specialists according to accepted diagnostic guidelines (EPOS 2012) (16); other existing studies have relied on self-diagnosis and/or used different criteria making direct comparisons with the existing literature more complicated. Whilst we realise EPOS2020 (1) has now superseded EPOS2012, the former was relevant at the time of the study being conducted. In the current era making comparisons between endotypes such as those with or without Type 2 mediated inflammation may provide further clinical relevance, but for now these are perhaps not adequately defined.

\section{Conclusion}

Patients with CRSwNP experience higher rates of asthma and lower rates of URTIs but otherwise do not demonstrate significant socioeconomic, comorbidity, lifestyle or quality of life issues other than for body pain and alcohol consumption. In the future, as endotyping replaces the current phenotypes and means of sampling larger sections of the populations become easier, it will be useful to revisit these findings through further epidemiological study.

\section{Declarations}

\section{Ethical approval and consent to participate}

The CRES was approved by the Oxford C Research Ethics Committee (Ref: 07/H0606/100), sponsored by the University of East Anglia (UEA).

\section{Consent for publication}

Not applicable

\section{Availability of data and material}

Not applicable

\section{Funding}

The study was funded by the Anthony Long Trust (postage costs) and the Bernice Bibby Trust (research nurse time).

\section{Competing interests}

None.

\section{Author contributions}

According to the ICMJE authorship criteria:

1. substantial contributions to conception and design of, or acquisition of data or analysis and interpretation of data

2. drafting the article or revising it critically for important intellectual content

3. final approval of the version to be published

Allan Clark 1, 2, 3

Carl Philpott 1, 2, 3

Ngan Hong Ta 2,3

Remaining authors 1, 3 


\section{Acknowledgements}

The CRES group of otorhinolaryngologists who recruited patients to the study.

Jane Woods, Research Nurse at the James Paget University Hospital for her dedication to the study.

\section{References}

1. Fokkens WJ, Lund VJ, Hopkins C, et al. European Position Paper on Rhinosinusitis and Nasal Polyps 2020. Rhinology. 2020;58(Suppl S29):1-464.

2. Philpott CM, Erskine S, Hopkins C, et al. Prevalence of asthma, aspirin sensitivity and allergy in chronic rhinosinusitis: data from the UK National Chronic Rhinosinusitis Epidemiology Study. Respir Res. 2018;19(1):129.

3. Rocha V, Soares S, Stringhini S, Fraga S. Socioeconomic circumstances and respiratory function from childhood to early adulthood: a systematic review and meta-analysis. BMJ Open. 2019;9(6):e027528.

4. Masoompour SM, Mahdaviazad H, Ghayumi SMA. Asthma and its related socioeconomic factors: The Shiraz Adult Respiratory Disease Study 2015. Clin Respir J. 2018;12(6):2110-2116.

5. Philpott C, Erskine S, Hopkins C, et al. A case-control study of medical, psychological and socio-economic factors influencing the severity of chronic rhinosinusitis. Rhinology.2016;54(2):134-140.

6. Geramas I, Terzakis D, Hatzimanolis E, Georgalas C. Social Factors in the Development of Chronic Rhinosinusitis: a Systematic Review.Curr Allergy Asthma Rep. 2018;18(2):7.

7. Hutson K, Clark A, Hopkins C, et al. Smoking as a modifying factor in chronic rhinosinusitis. JAMA Otolaryngology-Head $\& 3$ Neck Surgery. 2020;Under review.

8. Ahn J-C, Kim J-W, Lee CH, Rhee C-S. Prevalence and Risk Factors of Chronic Rhinosinusitus, Allergic Rhinitis, and Nasal Septal Deviation: Results of the Korean National Health and Nutrition Survey 20082012.JAMA otolaryngology- head \&3 neck surgery. 2016;142:162-167.

9. Bergmark RW, Hoehle LP, Chyou D, et al. Association of Socioeconomic Status, Race and Insurance Status with Chronic Rhinosinusitis Patient-Reported Outcome Measures. Otolaryngology - Head and Neck Surgery (United States). 2018;158:571-579.

10. Geramas I, Terzakis D, Hatzimanolis E, Georgalas C. Social Factors in the Development of Chronic Rhinosinusitis: a Systematic Review.Current Allergy $\& 3$ Asthma Reports. 2018;18:7.

11. Philpott C, Erskine S, Hopkins C, et al. A case-control study of medical, psychological and socio-economic factors influencing the severity of chronic rhinosinusitis. Rhinology. 2016;54:134-140.

12. Erskine SE, Verkerk MM, Notley C, Williamson IG, Philpott CM. Chronic rhinosinusitis: patient experiences of primary and secondary care - a qualitative study. Clin Otolaryngol. 2016;41:8-14.

13. Erskine S, Hopkins C, Kumar N, et al. A cross sectional analysis of a case-control study about quality of life in CRS in the UK; a comparison between CRS subtypes. Rhinology. 2016;54(4):311-315.

14. Erskine S, Hopkins C, Clark A, Philpott C, al e. SNOT-22 in a control population. Clin Otolaryngol. 2016; In press.

15. Erskine S, Notley C, Wilson A, Philpott C. Managing Chronic Rhinosinusitis and Respiratory Disease: A qualitative study of triggers and interactions. J Asthma. 2014:1-18.

16. Erskine SE, Verkerk MM, Notley C, Williamson IG, Philpott CM. Chronic Rhinosinusitis: Patient Experiences of Primary and Secondary Care - A Qualitative Study. Clin Otolaryngol. 2015. 
17. Philpott C, Hopkins C, Erskine S, et al. The burden of revision sinonasal surgery in the UK-data from the Chronic Rhinosinusitis Epidemiology Study (CRES): a cross-sectional study. Bmj Open.2015;5(4).

18. Erskine SE, Hopkins C, Clark A, et al. Chronic rhinosinusitis and mood disturbance. Rhinology. 2017;55(2):113-119.

19. Maniakas A, Desrosiers M, Asmar MH, et al. Eustachian tube symptoms are frequent in chronic rhinosinusitis and respond well to endoscopic sinus surgery. Rhinology. 2018;56:118-121.

20. Philpott C, Erskine S, Smith R, et al. Current use of baseline medical treatment in chronic rhinosinusitis: Data from the National Chronic Rhinosinusitis Epidemiology Study (CRES). Clin Otolaryngol. 2018;43(2):509-524.

21. Philpott CM, Smith R, Davies-Husband CR, et al. Exploring the association between ingestion of foods with higher potential salicylate content and symptom exacerbation in chronic rhinosinusitis. Data from the National Chronic Rhinosinusitis Epidemiology Study.Rhinology. 2019;57(4):303-312.

22. Fokkens WJ, Lund VJ, Mullol J, et al. European Position Paper on Rhinosinusitis and Nasal Polyps 2012. Rhinol Suppl. 2012(23):3 p preceding table of contents, 1-298.

23. Health Survey for England. 2018; https://digital.nhs.uk/data-andinformation/publications/statistical/health-survey-for-england/2018/health-survey-for-england-2018-datatables.

24. Hopkins C, Browne JP, Slack R, et al. The national comparative audit of surgery for nasal polyposis and chronic rhinosinusitis. Clin Otolaryngol. 2006;31(5):390-398.

25. Zhang Y, Gevaert E, Lou H, et al. Chronic rhinosinusitis in Asia.J Allergy Clin Immun. 2017;140:12301239.

26. Lu-Myers Y, Deal AM, Miller JD, et al. Comparison of Socioeconomic and Demographic Factors in Patients with Chronic Rhinosinusitis and Allergic Fungal Rhinosinusitis. Otolaryngol Head Neck Surg.2015;153:137-143.

27. Beswick DM, Mace JC, Rudmik L, et al. Socioeconomic factors impact quality of life outcomes and olfactory measures in chronic rhinosinusitis. Int Forum Allergy Rhinol. 2019;9(3):231-239.

28. Wahid NW, Smith R, Clark A, Salam M, Philpott CM. The socioeconomic cost of chronic rhinosinusitis study. Rhinology.2020;58(2):112-125.

29. Philpott CM, Smith R, Davies-Husband CR, et al. Exploring the association between ingestion of foods with higher potential salicylate content and symptom exacerbation in chronic rhinosinusitis. Data from the National Chronic Rhinosinusitis Epidemiology Study.Rhinology. 2019.

30. Sin DD, Wells H, Svenson LW, Man SF. Asthma and COPD among aboriginals in Alberta, Canada. Chest. 2002;121(6):1841-1846.

31. Corvalán C, Amigo H, Bustos P, Rona RJ. Socioeconomic risk factors for asthma in Chilean young adults. Am J Public Health.2005;95(8):1375-1381.

32. Ratageri VH, Kabra SK, Dwivedi SN, Seth V. Factors associated with severe asthma. Indian Pediatr. 2000;37(10):1072-1082.

Tables

Table 1: Comparison of comorbidities between CRSSsNP and CRSwNP. 


\begin{tabular}{|c|c|c|c|c|c|c|}
\hline Co-morbidity & $\begin{array}{l}\text { CRSsNP } \\
(\mathrm{n}=553)\end{array}$ & $\begin{array}{l}\text { CRSwNPs } \\
(n=651)\end{array}$ & Unadjusted & Unadjusted & Adjusted & Adjusted \\
\hline & $\mathrm{N}(\%)$ & $\mathrm{N}(\%)$ & $\begin{array}{l}\text { OR }(95 \% \\
\text { CI })\end{array}$ & $\mathrm{p}$-value & $\begin{array}{l}\text { OR }(95 \% \\
\text { CI })^{1}\end{array}$ & p-value \\
\hline Asthma & $117(21.2 \%)$ & $303(46.9 \%)$ & $\begin{array}{l}3.29 \\
(2.55,4.25)\end{array}$ & $<0.001$ & $\begin{array}{l}3.67 \\
(2.70,4.98)\end{array}$ & $<0.001$ \\
\hline COAD & $19(3.4 \%)$ & $35(5.4 \%)$ & $\begin{array}{l}1.61 \\
(0.91,2.52)\end{array}$ & 0.102 & $\begin{array}{l}1.26 \\
(0.64,2.47)\end{array}$ & 0.500 \\
\hline Bronchiectasis & $30(5.4 \%)$ & $43(6.7 \%)$ & $\begin{array}{l}1.24 \\
(0.77,2.02)\end{array}$ & 0.375 & $\begin{array}{l}0.94 \\
(0.55,1.61)\end{array}$ & 0.826 \\
\hline Diabetes & $31(5.6 \%)$ & $34(5.3 \%)$ & $\begin{array}{l}0.94 \\
(0.57,1.54)\end{array}$ & 0.794 & $\begin{array}{l}0.66 \\
(0.38,1.16)\end{array}$ & 0.147 \\
\hline Hypothyroidism & $30(5.4 \%)$ & $32(5.0 \%)$ & $\begin{array}{l}0.91 \\
(0.55,1.52)\end{array}$ & 0.718 & $\begin{array}{l}1.30 \\
(0.74,2.28)\end{array}$ & 0.370 \\
\hline Immunodeficiency & y14 $(2.5 \%)$ & $15(2.3 \%)$ & $\begin{array}{l}0.92 \\
(0.44,1.92)\end{array}$ & 0.817 & $\begin{array}{l}1.16 \\
(0.50,2.70)\end{array}$ & 0.728 \\
\hline $\begin{array}{l}\text { Autoimmune } \\
\text { disorder }\end{array}$ & $37(6.7 \%)$ & $25(3.9 \%)$ & $\begin{array}{l}0.56 \\
(0.33,0.95)\end{array}$ & 0.030 & $\begin{array}{l}0.51 \\
(0.28,0.93)\end{array}$ & 0.029 \\
\hline $\begin{array}{l}\text { Ciliary } \\
\text { dysmotility }\end{array}$ & $4(0.7 \%)$ & $0(0.0 \%)$ & & $0.045^{2}$ & & \\
\hline $\begin{array}{l}\text { Number of } \\
\text { colds per }\end{array}$ & $\begin{array}{l}\text { Number of } \\
\text { colds per }\end{array}$ & $\begin{array}{l}\text { Number of } \\
\text { colds per }\end{array}$ & $\begin{array}{l}\text { Number of } \\
\text { colds per }\end{array}$ & $\begin{array}{l}\text { Number of } \\
\text { colds per }\end{array}$ & $\begin{array}{l}\text { Number of } \\
\text { colds per }\end{array}$ & $\begin{array}{l}\text { Number of } \\
\text { colds per }\end{array}$ \\
\hline $\begin{array}{l}\text { year } \\
\text { never }\end{array}$ & $\begin{array}{l}\text { year } \\
14(2.5 \%)\end{array}$ & $\begin{array}{l}\text { year } \\
23(3.6 \%)\end{array}$ & year & $\begin{array}{l}\text { year } \\
<0.001\end{array}$ & year & year \\
\hline seldom & $216(39.2 \%)$ & $309(48.4 \%)$ & & & & \\
\hline often & $196(35.6 \%)$ & $201(31.5 \%)$ & & & & \\
\hline frequent & $125(22.7 \%)$ & $106(16.6 \%)$ & & & & \\
\hline
\end{tabular}

${ }^{1}$ adjusted for age, sex, asthma and aspirin sensitivity

2 Fisher's exact test

Table 2: Comparison of quality of life between CRSSsNP and CRSwNP.

\begin{tabular}{|c|c|c|c|c|c|c|}
\hline Co-morbidity & $\begin{array}{l}\text { CRSsNP } \\
(\mathrm{n}=553)\end{array}$ & $\begin{array}{l}\text { CRSwNPs } \\
(n=651)\end{array}$ & Unadjusted & Unadjusted & Adjusted $^{1}$ & Adjusted $^{1}$ \\
\hline & $\mathrm{N}(\%)$ & $\mathrm{N}(\%)$ & $\begin{array}{l}\text { Mean } \\
\text { difference } \\
(95 \% \mathrm{CI})\end{array}$ & p-value & $\begin{array}{l}\text { Mean } \\
\text { difference } \\
(95 \% \mathrm{CI})\end{array}$ & p-value \\
\hline $\begin{array}{l}\text { Vitality, } \\
\text { mean (SD) }\end{array}$ & $50.97(23.35)$ & $54.81(22.98)$ & $\begin{array}{l}3.84 \\
(1.17,6.51)\end{array}$ & 0.005 & $\begin{array}{l}1.64 \\
(-1.29,4.57)\end{array}$ & 0.273 \\
\hline $\begin{array}{l}\text { Physical } \\
\text { Function, } \\
\text { mean (SD) }\end{array}$ & $71.07(28.26)$ & $72.76(26.31)$ & $\begin{array}{l}1.70 \\
(-1.44,4.84)\end{array}$ & 0.289 & $\begin{array}{l}2.30 \\
(-1.12,4.84)\end{array}$ & 0.187 \\
\hline $\begin{array}{l}\text { Body Pain, } \\
\text { mean (SD) }\end{array}$ & $63.34(27.14)$ & $70.66(25.89)$ & $\begin{array}{l}7.32 \\
(4.26,10.37)\end{array}$ & $<0.001$ & $\begin{array}{l}5.77 \\
(2.40,9.13)\end{array}$ & 0.001 \\
\hline $\begin{array}{l}\text { General } \\
\text { Health, } \\
\text { mean (SD) }\end{array}$ & $53.13(22.97)$ & $53.45(23.16)$ & $\begin{array}{l}0.31 \\
(-2.35,2.97)\end{array}$ & 0.818 & $\begin{array}{l}-0.77 \\
(-3.71,2.17)\end{array}$ & 0.607 \\
\hline
\end{tabular}




\begin{tabular}{|c|c|c|c|c|c|c|}
\hline Co-morbidity & $\begin{array}{l}\text { CRSsNP } \\
(\mathrm{n}=553)\end{array}$ & $\begin{array}{l}\text { CRSwNPs } \\
(\mathrm{n}=651)\end{array}$ & Unadjusted & Unadjusted & Adjusted $^{1}$ & Adjusted $^{1}$ \\
\hline $\begin{array}{l}\text { Role- } \\
\text { Physical, } \\
\text { mean (SD) }\end{array}$ & $67.48(40.86)$ & $71.19(39.61)$ & $\begin{array}{l}3.71 \\
(-0.92,8.35)\end{array}$ & 0.0016 & $\begin{array}{l}2.47 \\
(-2.68,7.62)\end{array}$ & 0.347 \\
\hline $\begin{array}{l}\text { Role } \\
\text { Emotional, } \\
\text { mean (SD) }\end{array}$ & $78.13(37.05)$ & $82.87(33.51)$ & $\begin{array}{l}4.74 \\
(0.68,8.79)\end{array}$ & 0.022 & $\begin{array}{l}2.71 \\
(-1.76,7.18)\end{array}$ & 0.234 \\
\hline $\begin{array}{l}\text { Social } \\
\text { Functioning, } \\
\text { mean (SD) }\end{array}$ & $73.47(27.76)$ & $78.19(25.18)$ & $\begin{array}{l}4.72 \\
(1.68,7.77)\end{array}$ & 0.002 & $\begin{array}{l}2.96 \\
(-0.38,6.30)\end{array}$ & 0.083 \\
\hline $\begin{array}{l}\text { Mental } \\
\text { Health, } \\
\text { mean (SD) }\end{array}$ & $69.58(19.82)$ & $72.72(18.23)$ & $\begin{array}{l}3.14 \\
(0.95,5.33)\end{array}$ & 0.005 & $\begin{array}{l}0.81 \\
(-1.52,3.15)\end{array}$ & 0.495 \\
\hline $\begin{array}{l}\text { Physical } \\
\text { Health, } \\
\text { mean (SD) }\end{array}$ & $61.14(22.40)$ & $64.47(21.05)$ & $\begin{array}{l}3.33 \\
(0.83,5.83)\end{array}$ & 0.009 & $\begin{array}{l}2.23 \\
(-0.52,4.97)\end{array}$ & 0.112 \\
\hline $\begin{array}{l}\text { Mental } \\
\text { Health, } \\
\text { mean (SD) }\end{array}$ & $65.07(20.81)$ & $68.40(19.47)$ & $\begin{array}{l}3.33 \\
(1.01,5.65)\end{array}$ & 0.005 & $\begin{array}{l}1.46 \\
(-1.05,3.96)\end{array}$ & 0.254 \\
\hline $\begin{array}{l}\text { TOTAL } \\
\text { SF36 Score, } \\
\text { mean (SD) }\end{array}$ & $65.92(21.41)$ & $69.61(19.63)$ & $\begin{array}{l}3.70 \\
(1.34,6.06)\end{array}$ & 0.002 & $\begin{array}{l}2.24 \\
(-0.33,4.81)\end{array}$ & 0.088 \\
\hline
\end{tabular}

1 adjusted for age and sex

Table 3: Comparison of Socio-economic status between CRSSsNP and CRSwNP.

\begin{tabular}{|c|c|c|c|c|c|c|}
\hline Variable & $\begin{array}{l}\text { CRSsNP } \\
(\mathrm{n}=553)\end{array}$ & $\begin{array}{l}\text { CRSwNPs } \\
(\mathrm{n}=651)\end{array}$ & Unadjusted & Unadjusted & Adjusted1 & Adjusted1 \\
\hline & $\mathrm{N}(\%)$ & $\mathrm{N}(\%)$ & $\begin{array}{l}\text { Mean } \\
\text { difference } \\
(95 \% \mathrm{CI})\end{array}$ & p-value & $\begin{array}{l}\text { Mean } \\
\text { difference } \\
(95 \% \mathrm{CI})\end{array}$ & p-value \\
\hline IMD score & $16.49(10.60)$ & $16.66(9.88)$ & $\begin{array}{l}0.17 \\
(-1.06,1.40)\end{array}$ & 0.787 & $\begin{array}{l}0.18 \\
(-1.20,1.56)\end{array}$ & 0.795 \\
\hline Income & $\begin{array}{l}39426.13 \\
(30567.75)\end{array}$ & $\begin{array}{l}41203.37 \\
(30478.51)\end{array}$ & $\begin{array}{l}1777.23(- \\
2580.13,6134.59)\end{array}$ & 0.4241 & $\begin{array}{l}2467.90(- \\
2277.50,7213.29)\end{array}$ & 0.3081 \\
\hline & Qualifications: & Qualifications: & Qualifications: & Qualifications: & Qualifications: & Qualifications: \\
\hline A-LEVEL & $36(9.2 \%)$ & $51(10.9 \%)$ & & 0.2 .12 & & \\
\hline NVQ & $65(16.6 \%)$ & $78(16.6 \%)$ & & & & \\
\hline Degree & $135(34.5 \%)$ & $138(29.4 \%)$ & & & & \\
\hline Higher & $46(11.8 \%)$ & $76(16.2 \%)$ & & & & \\
\hline $\begin{array}{l}\text { GCSE/A- } \\
\text { level }\end{array}$ & $\begin{array}{l}\text { Qualification } \\
\text { (grouped): } \\
144(36.9 \%)\end{array}$ & $\begin{array}{l}\text { Qualification } \\
\text { (grouped): } \\
176(37.6 \%)\end{array}$ & $\begin{array}{l}\text { Qualification } \\
\text { (grouped): } \\
1\end{array}$ & $\begin{array}{l}\text { Qualification } \\
\text { (grouped): }\end{array}$ & $\begin{array}{l}\text { Qualification } \\
\text { (grouped): } \\
1\end{array}$ & $\begin{array}{l}\text { Qualification } \\
\text { (grouped): }\end{array}$ \\
\hline
\end{tabular}




\begin{tabular}{lllllll}
\hline Variable & $\begin{array}{l}\text { CRSsNP } \\
(\mathrm{n}=553)\end{array}$ & $\begin{array}{l}\text { CRSwNPs } \\
(\mathrm{n}=651)\end{array}$ & Unadjusted & Unadjusted & Adjusted1 & Adjusted1 \\
\hline $\begin{array}{l}\text { NVQ/degree/ } \\
\text { higher } \\
\text { degree }\end{array}$ & $246(63.1 \%)$ & $292(62.4 \%)$ & 0.97 & 0.837 & 1.01 & 0.946 \\
\hline
\end{tabular}

${ }^{1}$ based on a non-parametric bootstrap with 10,000 replications.

${ }^{2}$ based on a chi-squared test

3 Odds ratio $(95 \%$ CI)

Table 4: Comparison of life-style variables between CRSSsNP and CRSwNP.

\begin{tabular}{lllll}
\hline Variable & & CRSsNP (n=553) & CRSwNPs (n=651) & p-value $^{1}$ \\
\hline \multirow{3}{*}{ Alcohol } & & $\mathrm{N}(\%)$ & $\mathrm{N}(\%)$ & \\
& None & $196(35.8 \%)$ & $180(28.1 \%)$ & 0.032 \\
& 1 to 10 & $269(49.1 \%)$ & $342(53.4 \%)$ & \\
Smoke & 11 to 20 & $73(13.3 \%)$ & $107(16.7 \%)$ & \\
& $>20$ & $10(1.8 \%)$ & $11(1.7 \%)$ & \multirow{2}{*}{0.25} \\
& None & $470(86.1 \%)$ & $574(89.7 \%)$ & \\
Living location & 1 to 10 & $46(8.4 \%)$ & $41(6.4 \%)$ & \\
& 11 to 20 & $25(4.6 \%)$ & $19(3.0 \%)$ & \\
& $>20$ & $5(0.9 \%)$ & $6(0.9 \%)$ & \\
Occupation & Village & $195(37.9 \%)$ & $222(35.7 \%)$ & \\
& Suburbs & $160(31.1 \%)$ & $229(36.9 \%)$ & \\
& Urban & $159(30.9 \%)$ & $170(27.4 \%)$ & \\
& Indoor & $354(70.2 \%)$ & $422(70.9 \%)$ & \\
& Outdoor & $20(4.0 \%)$ & $24(4.0 \%)$ & \\
& Unclear & $130(25.8 \%)$ & $149(25.0 \%)$ & \\
\hline
\end{tabular}

${ }^{1}$ based on a chi-squared test

Figure Legends

Figure 1. Participant flow diagram

Figure 2: A histogram of household income by group

\section{Hosted file}

image1.emf available at https://authorea.com/users/314083/articles/484348-socioeconomiccomorbidity-lifestyle-and-quality-of-life-comparisons-between-chronic-rhinosinusitisphenotypes-data-from-the-national-chronic-rhinosinusitis-epidemiology-study

Appendix 1: Study questionnaire 
-

Ret. $\square \square \square \square$

Please try to fill in ALL parts of the questionnaire, even if you do not have sinus problems and do not feel they are directly relevant to you.

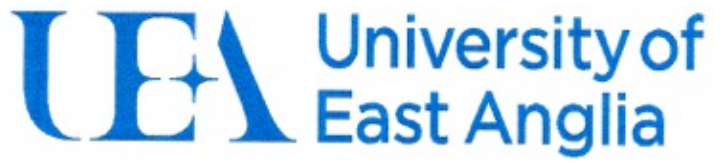

\section{CHRONIC RHINOSINUSITIS EPIDEMIOLOGY STUDY (CRES)}

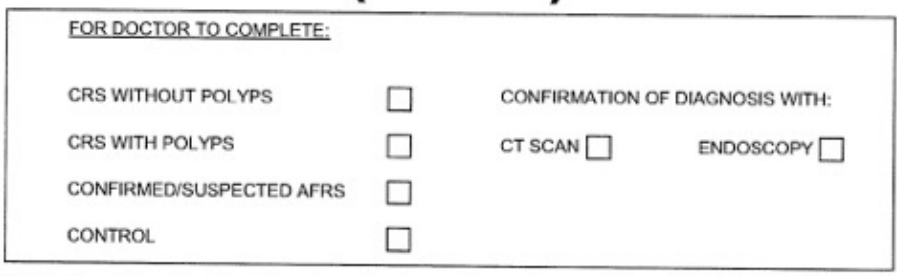

\section{RECRUITMENT SITE}

JPUH $\square$

LDH $\square$

Cl $\square$

IRH

OUH $\square$

$\mathrm{RCH}$

DBH $\square$

$$
\begin{aligned}
& \text { NNUH } \square \\
& \text { RSCH } \square \\
& \text { SRI } \square \\
& \text { HEFT } \square \\
& \text { SAMBU } \square \\
& \text { RGH } \square \\
& \text { Other } \square
\end{aligned}
$$

wwL $\square$

GuYs $\square$

SGH

$\mathrm{QEH}$

СтHB

AUHNT

SPIRE

QMC

BCUH

STH

WнH

WHH $\square$

NGH

$\mathrm{FH}$

RAH

WI

PHNT $\square$

Please return the questionnaire to the Norwich Modical School, UEA, Nonwich - for the attention of Mr Carl Philpott

-

Version 4.3 2000312

\section{|||||||||||||||||||||||||||||}

Page 1 